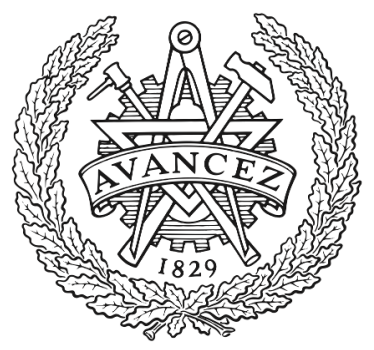

CHALMERS

UNIVERSITY OF TECHNOLOGY

\title{
Prediction of dynamic responses of FSRU-LNGC side-by-side mooring system
}

Downloaded from: https://research.chalmers.se, 2023-04-26 10:09 UTC

Citation for the original published paper (version of record):

Yue, J., Kang, W., Mao, W. et al (2020). Prediction of dynamic responses of FSRU-LNGC side-by-side mooring system. Ocean Engineering, 195.

http://dx.doi.org/10.1016/j.oceaneng.2019.106731

N.B. When citing this work, cite the original published paper. 


\title{
Prediction of dynamic responses of FSRU-LNGC side-by-side mooring system
}

\author{
Jingxia Yue $^{\mathrm{a}, *}$, Weili Kang ${ }^{\mathrm{a}}$, Wengang Mao ${ }^{\mathrm{b}}$, Pengfei Chen ${ }^{\mathrm{c}}$, Xi Wang ${ }^{\mathrm{d}}$

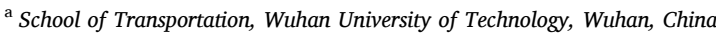 \\ ${ }^{\mathrm{b}}$ Department of Mechanics and Maritime Sciences, Chalmers University of Technology, Gothenburg, Sweden \\ c Shanghai Investigation, Design \& Research Institute Co., Ltd, Shanghai, China \\ ${ }^{\mathrm{d}}$ CCS Wuhan Rules \& Research Institute, Wuhan, China
}

\section{A R T I C L E I N F O}

\section{Keywords:}

FSRU

Side-by-side mooring

Multi-floating mooring system

Dynamic response

The damping lid method

\begin{abstract}
A B S T R A C T
Floating Storage and Regasification Unit (FSRU) becomes one of the most popular equipment in the industry for providing clean energy because of its technical, economic and environmental features. The interaction between the FSRU and Liquified Natural Gas Carrier (LNGC) under the combined loads from wind, wave and current is quite complex to model. In this paper, a configuration for the offloading operation of the FSRU-LNGC side-byside mooring system is proposed to predict the motion responses, forces on the cables and fenders of the multifloating mooring system. The damping lid method is adopted to improve the overestimated hydrodynamic coefficients calculated from conventional potential flow theory in the frequency domain. The dynamic response of the side-by-side mooring system including six degrees of freedom motion, relative motions, cable tensions and fender forces are provided and analyzed. The numerical results are validated using the experimental data. The proposed coupled analysis model and the numerical analysis can properly predict the dynamic response of the multi-floating mooring. The sensitivity analysis of pretension of the connecting cables on the dynamic responses of the two vessels are provided. Moreover, the non-dimensional damping parameters can be acted as a good reference to the dynamic response analysis of similar multi-floating mooring systems.
\end{abstract}

\section{Introduction}

With the wide application of Liquified Natural Gas (LNG), the Floating Storage and Regasification Unit (FSRU) has attracted wide attention. During the LNG offloading operation, the multi-floating mooring system consisting of a FSRU and an LNG Carrier (LNGC) can be in side-by-side or tandem configuration. The side-by-side offloading operation for the multi-floating mooring system is of more interest because more accurate analysis of hydrodynamic interactions between FSRU and LNGC moored in close proximity is needed (Hong et al., 2005). To get accurate dynamic responses of the mooring system, relative motion of the two vessels, and the load distribution on the cables and fenders due to wind, wave and current is essential to the side-by-side offloading operation safety. During the prediction of the system dynamic response, the following items should be considered carefully:

The arrangement of the side-by-side configuration;
The simulation of the viscous effect of free surface between FSRU and LNGC;

- The detailed analysis of the dynamic responses of the multi-floating mooring system;

For the multi-floating mooring system in side-by-side offloading operation, experimental methods are still recognized as the most reliable techniques to obtain of the dynamic responses (Zhao et al., 2017). For example, Hong (Hong et al., 2005) presented a higher-order boundary element method (HOBEM) combined with generalized mode approach and verified it by the experiment. Numerical results using HOBEM show good agreements with experiments for global and local motion response and wave drift force of side-by-side moored vessels in both regular and irregular waves. However, exception is observed for a wave drift force in very narrow frequency region where strong interaction occurs due to Helmholtz resonance. Zhao (Zhao et al., 2017) provided an experimental investigation on dynamic responses of the connection system in the FLNG system during side-by-side offloading operations. In this

\footnotetext{
* Corresponding author.

E-mail address: j.yue@whut.edu.cn (J. Yue).
} 
research, relationships between relative vessel motion and the load born by the connection system are obtained and features of dynamic connection system responses are summarized, but the detailed discussions on mooring system are not presented. Inoue (Inoue and Islam, 1999) compared numerical and experimental results of parallel connected FPSO and LNG carriers in waves. A numerical multiple body simulation model for the reliable prediction of relative motions and mooring loads during side-by-side offloading operations is also developed. Huang (Huang et al., 2018) provided the numerical approach and model for gangway response between nonparallel side-by-side flotel and FPSO to predict the physics of various gangway responses. Numerical simulation and measurement reach pretty good agreement, which shows that the established physical model can properly represent physics of gangway response. But this numerical approach and model are not applicable to the side-by-side mooring system. Pessoa (Pessoa et al., 2016) validated a frequency domain numerical method for calculating second order responses to irregular wave excitations through comparisons with experimental data obtained in an offshore wave basin. It is shown that the second order low frequency loads cannot be neglected when calculating the tension on the side by side mooring system. Zhao (Zhao et al., 2013) studied two different ways of connecting FLNG vessel and LNG carrier. The numerical results show that there is significant difference at the hydrodynamic performance in the two ways of tandem offloading operations, which means that the connection between FLNG vessel and LNG carrier plays an important role. Vieira (Vieira et al., 2018) investigated the influence of the liquid inside the tanks in the wave behavior of FLNG vessels in side-by-side offloading operations experimentally. The study showed that the analysis of coupled systems considering all the effects is very important for the correct definition of the dynamics of the vessels, which include coupled hydrodynamic between vessels, the impact of LNG tanks free surface on systems motions, the resonance effect on the free surface of the gap between hulls and the influence of mooring lines and fenders. However, the influence of each factor on the dynamic responses of the system is not quantified.

Theoretical and numerical researches on the multi-floating mooring system were studied in order to analyze the side-by-side configuration realistically. Because of the complex multi-floating mooring system, the viscous effect of free surface between two ships is very obvious. Some assumptions and simplifications should be adopted to obtain more correct numerical results (Huang et al., 2018). Newman (Newman, 2001; Newman and Nicholas, 1977) reviewed the extensive analytical results and accomplishments from numerical simulation. Buchner et al. (2001) introduced a rigid lid on the free surface between the vessels within the multi-body diffraction analysis to suppress the unrealistic resonant wave oscillations. Similar studies were also shown by Naciri (Naciri et al., 2007), which verified the simulation results through experiment. Chen (2004) proposed the damping lid method. They added a dissipative term in the free surface boundary condition inside the gap. Chen and Malenica (2005) discussed the damping method applied in the multibody problem. The method basically reduced the source strength by adjusting the terms associated with the damping effects.

Previous research activities described above focused on the detailed study of partial problems, such as the hydrodynamics interaction, the resonant wave oscillations of the free surface between the side-by-side vessels, or the implementation of newly developed methods. However, researches on the prediction of dynamic responses of the side-by-side configuration are far from enough. More experimental researches should be carried out to illustrate response characteristics of multifloating mooring system. The objective of this paper is to propose a safe and reliable configuration of FSRU-LNGC multi-floating mooring system and to predict the dynamic response of the system. In the numerical calculation, the damping lid method is presented to correct the distortion of hydrodynamic coefficients caused by fluid resonance between two floating bodies, so as to obtain a more realistic dynamic response to verify whether the configuration meets the specification requirements. Corresponding model tests were also carried out to validate the numerical results. In order to achieve the above objective, Section 2 gives the description of the configuration, Section 3 provides the numerical calculation method and calculation process, Section 4 introduces the model test set up, Section 5 verifies the numerical results according to the experiment and carries out a detailed analysis of the dynamic response of the system, Section 6 analyzes the sensitivity of the dynamic response of the system to the pretension of the connecting cable.

\section{Description of the FSRU-LNGC side-by-side configuration}

\subsection{Features of the FSRU-LNGC side-by-side mooring system}

The conceptual FSRU-LNGC Ship to Ship Mooring Arrangement developed by Dalian Shipbuilding Industry Engineering and Research Institute of China is selected as a reference. The side-by-side configuration of the multi-floating mooring system is proposed based on the Mooring Equipment Guidelines (OCIMF, 2008) and taking into account the configuration of the wharf. The FSRU-LNGC side-by-side mooring system consists of FSRU-wharf mooring system and FSRU-LNGC connecting system, the general arrangement of which is illustrated in Fig. 1. The FSRU is designed to be moored at the wharf, and the LNGC is connected alongside the FSRU during the side-by-side offloading operation. Full loaded FSRU and ballast LNGC are considered in this study because test results showed more severe motions and load responses in this loading condition (OCIMF, 2008). The principal dimensions of the FSRU and LNGC are introduced in Table 1 . The mooring system is designed to be a "4-3-2" symmetrical arrangement and consists of 18 cables and 4 fenders. Similarly, the connecting system consists of 24 cables and 8 fenders and is designed to be a "2-2-3-3-2" symmetrical arrangement. The detailed particulars of the two systems are shown in Table 2 and Table 3. The side-by-side distance between FSRU and LNGC is set to be $4.5 \mathrm{~m}$, which is the same as the length of the fenders. It should be noted that the safety requirements can be satisfied when the loads of the cables or the forces of the fenders are less than their safe working load (SWL). In order to verify the safety and rationality of the above configuration, numerical calculation and test methods are used to analyze the dynamic response of the multi-floating mooring system. The analysis methods are shown in Section 3 and Section 4, respectively.

\subsection{Environmental condition}

In the numerical and experimental analysis, wave, wind and current are considered in the side-by-side offloading of the FSRU-LNGC multifloating mooring system. According to the long-term distribution data of coastal waves in China (Yangshan et al., 2007) and the Design Specification for LNG Terminals (Ministry of Communications of the People's Republic of China, 2009), the relevant parameters of the waves are determined. The Mooring Equipment Guidelines (OCIMF, 2008) gives detailed wind and current environment requirements for the system moored at the wharf. According to the guidelines (OCIMF, 2008), the

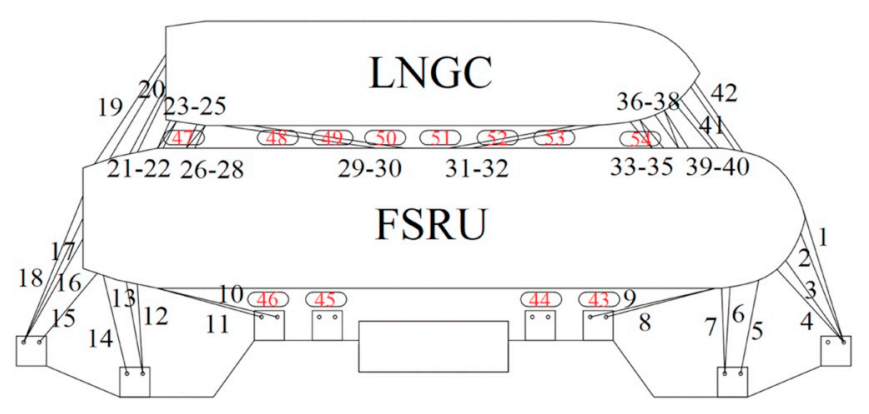

Fig. 1. The side-by-side configuration of the FSRU-LNGC mooring system. 
Table 1

Principal dimensions of the FSRU and LNGC.

\begin{tabular}{lllll}
\hline Item & Symbol & Unit & FSRU (full) & $\begin{array}{l}\text { LNGC } \\
\text { (ballast) }\end{array}$ \\
\hline Length over all & L & $\mathrm{m}$ & 340.5 & 290 \\
Length between perpendiculars & $L_{\mathrm{pp}}$ & $\mathrm{m}$ & 330 & 278 \\
Breath & $B$ & $\mathrm{~m}$ & 60 & 45.6 \\
Depth & $\mathrm{D}$ & $\mathrm{m}$ & 25.72 & 29 \\
Draft & $\mathrm{T}$ & $\mathrm{m}$ & 11.98 & 9.61 \\
Displacement & $\mathrm{M}$ & $\mathrm{MT}$ & 202246 & 95887 \\
Center of the gravity above base & KG & $\mathrm{m}$ & 17.14 & 12.53 \\
Center of the gravity from AP & LCG & $\mathrm{m}$ & 168.12 & 143.37 \\
Radius of roll gyration & Kxx & $\mathrm{m}$ & 20.42 & 18.78 \\
Radius of pitch gyration & Kyy & $\mathrm{m}$ & 83.62 & 72.77 \\
Radius of yaw gyration & Kzz & $\mathrm{m}$ & 86.95 & 74.18 \\
\hline
\end{tabular}

Table 2

Main parameters and attributes of the cables.

\begin{tabular}{llll}
\hline Item & Unit & Mooring system & Connecting system \\
\hline Diameter & $\mathrm{mm}$ & 52 & 40 \\
Weight in air & $\mathrm{kg} / \mathrm{m}$ & 1.46 & 0.881 \\
SWL & $\mathrm{kN}$ & 1734.6 & 1107.4 \\
\hline
\end{tabular}

Table 3

Main parameters and attributes of the fenders.

\begin{tabular}{|c|c|c|c|}
\hline Item & Unit & Mooring system & Connecting system \\
\hline Diameter length & $\mathrm{m} \quad \mathrm{m}$ & 4.59 & 4.59 \\
\hline Maximum deformation & $\mathrm{m}$ & 2.7 & 2.7 \\
\hline SWL & $\mathrm{kN}$ & 19600 & 19600 \\
\hline
\end{tabular}

relevant parameters of wind and current are determined. The irregular wave is described by a three-parameter JONSWAP spectrum with a significant wave height of $2 \mathrm{~m}$, a peak period of $8 \mathrm{~s}$ and a peak enhancement factor of 3.3. The mean velocity of the steady wind is $20 \mathrm{~m} / \mathrm{s}$. The current velocity near the surface is $1.1 \mathrm{~m} / \mathrm{s}$. In the model tests and the numerical simulations, wave and current approach the multi-floating mooring system with the heading Angle of 45 , wind approaches the system with the heading Angle of 90 .

\section{Numerical modeling}

During the operation, liquefied natural gas will be transferred from LNGC to FSRU. In the numerical simulation, the transfer is regarded as a quasi-static process, and only the coupled motion of the multi-floating mooring system in the initial state is studied. Numerical analysis is carried out in ANSYS-AQWA based on the potential flow theory (Hong et al., 2009). The AQWA-Line, AQWA-Librium and AQWA-Drift modules are used for frequency-domain calculation, static equilibrium calculation and time-domain calculation respectively. The hydrodynamic coefficients such as added mass, first-order and second-order wave drift force and potential damping of the two floating bodies are calculated in frequency-domain. The damping lid method is used to improve the conventional potential flow theory for the above-mentioned hydrodynamic coefficients. The static equilibrium position of FSRU and LNGC and the pretension of cables in the multi-floating mooring system are obtained by static equilibrium calculation under the given environment condition. The dynamic responses of the multi-floating mooring system

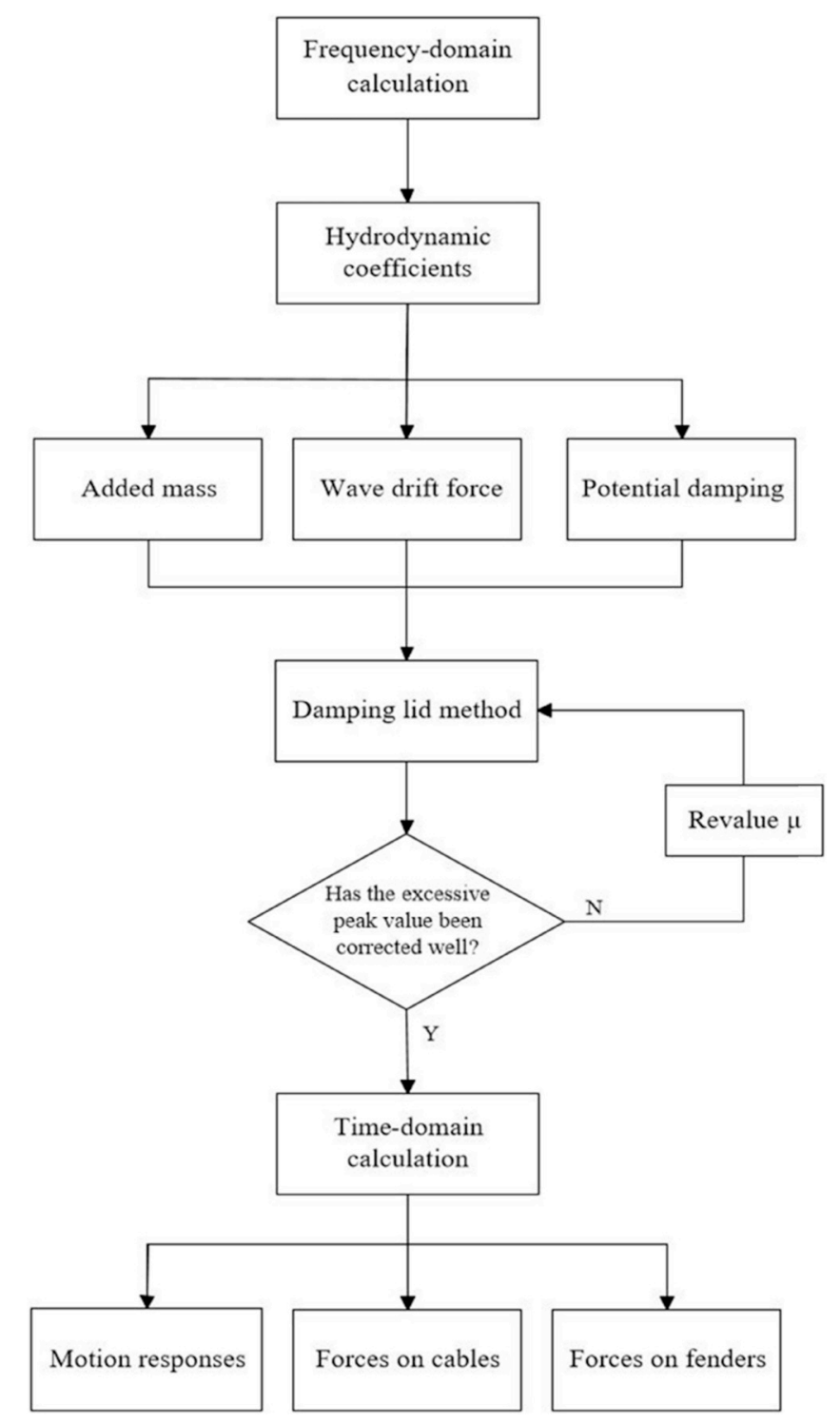

Fig. 2. Procedures to the numerical analysis to estimate the motion and forces of the LNGC and FSRU interaction under actual sea conditions.

are obtained through time-domain calculation. The calculation process is shown in Fig. 2.

\subsection{Frequency-domain analysis}

Based on the potential flow theory, the velocity potential satisfies the Laplace equation (Hong et al., 2009).

$\frac{\partial^{2} \Phi x, y, z, t}{\partial x^{2}} \quad \frac{\partial^{2} \Phi x, y, z, t}{\partial y^{2}} \quad \frac{\partial^{2} \Phi x, y, z, t}{\partial z^{2}} \quad 0$

where $\Phi x, y, z, t$ is the velocity potential function of the coordinates $x, y$ and $z$ and the time $t$.

The velocity potential can be expressed as

$\Phi x, y, z, t \quad \operatorname{Re} \varphi x, y, z e^{i w t}$ 
where $w$ is the oscillation frequency.

The $\Phi x, y, z, t$ can further be divided into the radiation potential $\varphi_{R} x, y, z$ and scattering potential $\varphi_{s} x, y, z$. Scattering potential $\varphi_{s} x, y, z$ can further be divided into incident-wave potential $\varphi_{I} x, y, z$ and diffraction potential $\varphi_{D} x, y, z$. Thus, the $\varphi(x, y, z)$ can be expressed as

$\varphi x, y, z \quad \varphi_{R} x, y, z \quad \varphi_{I} x, y, z \quad \varphi_{D} x, y, z$

The velocity potential can be transformed into the integral equation on the surface by using the Green formula. Each part of the potential in Eq. (3) can be solved under their corresponding boundary conditions. Wave forces acting on FSRU and LNGC can be obtained by adopting the incident-wave potential and diffraction potential through the Bernoulli equation. The hydrodynamic coefficients induced by the oscillation of the floating bodies can be solved by the radiation potential, like the damping forces and the added masses.

$a_{m n} w \quad \operatorname{Re}\left[\rho w \iint_{S_{0}} \varphi_{m} \frac{\partial \varphi_{n}}{\partial n} d s\right] \quad m, n \quad 1,2, \ldots, 6$

$c_{m n} w \quad \operatorname{Im}\left[\rho w \iint_{S_{0}} \varphi_{m} \frac{\partial \varphi_{n}}{\partial n} d s\right] \quad m, n \quad 1,2, \ldots, 6$

where $\varphi_{m}$ represents the induced velocity potential when the floating body is oscillating in direction $\mathrm{m}$ with a unit speed. $a_{m n} w$ and $c_{m n} w$ means the added mass and the potential damping in direction $m$ induced by the body oscillation in direction $\mathrm{n} . \rho$ is the density of the fluid, and $S_{0}$ is the wet surface area of the floating body.

\subsection{Improvement of hydrodynamic coefficients in frequency-domain analysis}

The theory of potential flow is not able to consider the viscosity and energy dissipation of the hydrodynamic interaction between two vessels. In the case of resonance, the hydrodynamic parameters of floating body calculated in frequency domain based on potential flow theory are too large and have obvious distortion. Therefore, the numerical calculation method based on the potential flow theory needs to simulate the damping due to the viscous separation of the fluid to model the real circumstance. The damping lid method was introduced in detail by Chen (2004) and the sensitivity of the results for this method was presented by Chen et al. (Chen and Malenica, 2005) and Chakrabarti (1978). In this paper, the damping lid method based on the fairly perfect fluid is used to add damping to the free surface between floating bodies. It results in a linear damping term in free surface boundary condition. The characteristics of the fairly perfect fluid are based on the assumption that the fluid particle is subjected to an internal force proportional to the magnitude of fluid velocity besides gravity. The internal force $F$ can be expressed as:

F $\quad \mu \nabla \Phi$

where $\Phi$ is the velocity potential and $\mu$ is the damping parameter and is defined as a positive value. The internal force is directly proportional to
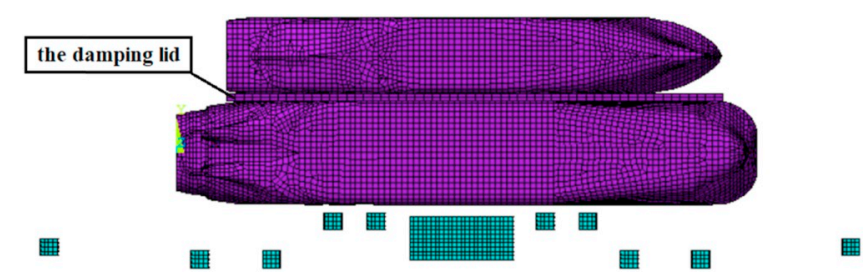

Fig. 3. Numerical models based on the fairly perfect fluid. the velocity of the fluid and opposite to its direction. The function of the inner force is the same as the viscous effect and energy dissipation of the fluid between two floating bodies, but the vortex is not introduced so that the existence of velocity potential is guaranteed. The nondimensional damping parameter of the lid is reasonably evaluated by referring to the model tests. Fig. 3 presents the numerical model of the FSRU-LNGC side-by-side mooring system with a lid added to the free surface between two ships to simulate the viscosity and the energy dissipation. The mesh area of the gap region is empirically defined as explained by Chen (Chen and Malenica, 2005), which generally covers the major part of the gap along the LNGC. The length and width of the damping lid are $290 \mathrm{~m}$ and $4.5 \mathrm{~m}$ respectively, which are the same as the length of LNGC and the width of the gap between the two ships.

Based on this fairly perfect fluid, the classical Bernoulli's equation is modified as:

$\frac{P}{\rho} \quad g z \quad \Phi_{t} \quad \frac{1}{2} \nabla \Phi^{2} \quad \mu \Phi \quad 0$

We define that the Cartesian coordinate system with xy-plane coincides with the calm water and positive $\mathrm{z}$-axis is pointing upwards. Then the wave elevation at the free surface can be expressed as:

$z \zeta x, y, t$

At the free surface, the pressure in Bernoulli 's equation is identical to the atmospheric pressure, that is:

$g \zeta \quad \Phi_{t} \quad \frac{1}{2} \nabla \Phi^{2} \quad \mu \Phi$

Additionally, fluid particles on the free surface always remain on the wave surface, which means that all the fluid particles on the free surface can only make tangential movement along the surface and the normal velocity of fluid particle is the same as that of the free surface. This condition generates the kinetic condition of the free surface:

$\zeta_{t} \quad \Phi_{x} \zeta_{x} \quad \Phi_{y} \zeta_{y} \quad \Phi_{z} \quad 0$

\subsection{Time-domain analysis}

In the multi-body modeling, the hydrodynamic interactions of the two floating bodies are also taken into consideration, in the form of coupled added masses and coupled retardation functions. The motion equations of the time-domain coupled analysis for FSRU or LNGC are as follows (Hong et al., 2009):

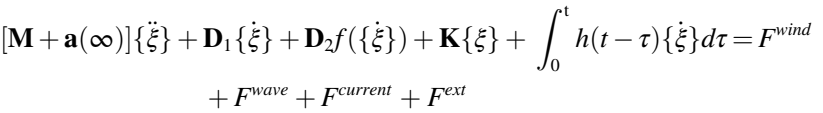

where $\boldsymbol{M}$ is the generalized mass matrix for the vessel, $\mathbf{a} \infty$ is the added mass matrix at the infinite frequency, $\boldsymbol{D}_{1}$ and $\boldsymbol{D}_{2}$ are the linear and quadratic damping matrices respectively, $\boldsymbol{K}$ is the hydrostatic restoring stiffness matrix. $F^{\text {wind }}, F^{\text {wave }}$ and $F^{\text {current }}$ represent the wind drag force, the wave drag force and the current drag force respectively. $F^{\text {ext }}$ represents any other forces. $\int_{0}^{t} h t \quad \tau\{\dot{\xi}\} d \tau$ means the retardation function matrix.

The hydrodynamic interaction between FSRU and LNGC needs to be considered in the time-domain calculation of the multi-floating mooring system. The effects of the hydrodynamic interaction on the frequency dependent added mass and the damping forces are included in the coupled added mass and the coupled retardation functions at the infinite frequency. Thus, the two $6 \quad 6$ matrices $\mathbf{M}$ a $\infty$ and $h t \quad \tau$ in Eq. (11) should be written as 1212 matrices respectively.

$$
\begin{array}{ccc}
\mathbf{M} \infty & \mathbf{M} \quad \mathbf{a} \infty_{i, i} \quad \mathbf{a} \infty^{i, j} \\
& \mathbf{a} \infty_{j, i} & \mathbf{a} \infty_{j, j}
\end{array}
$$




$$
\begin{array}{llllll} 
& & h t & \tau_{i, i} & h t & \tau_{i, j} \\
& h t & \tau_{j, i} & h t & \tau_{j, j}
\end{array}
$$

where the subscripts $i$ and $j$ represent the FSRU and LNGC respectively. It should be indicated that the item with the same indices such as $i, i$ or $j, j$ is equal to the item in the single vessel, and the item with the different indices like $i, j$ indicates the effect of LNGC on FSRU. Similarly, there is an item with a subscript as $j, i$.

Therefore, the time-domain coupled motion equation of multifloating mooring system can be expressed as:

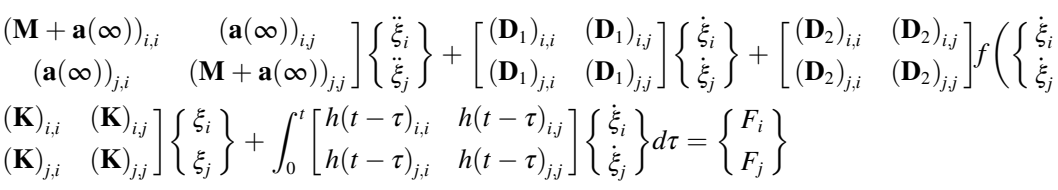

According to the experimental requirements, the basin can simulate various marine environmental conditions which consists of wind, wave and current and has adjustable water depth. The dimension of the basin is $50 \mathrm{~m}$ long, $40 \mathrm{~m}$ wide, $10 \mathrm{~m}$ in depth and the water depth was set at $0.938 \mathrm{~m}$, which is corresponding to actual water depth of $60 \mathrm{~m}$. Advanced equipment and measuring instruments are carefully calibrated before the tests to ensure the reliability of the measured data. For irregular waves, each test ran for more than $22.5 \mathrm{~min}$ corresponds to the $3 \mathrm{~h}$. The motion responses of the FSRU and LNGC in 6 degrees of freedom and the time series of the loads acting on the mooring system and connecting system were recorded with a sampling frequency of $40 \mathrm{~Hz}$.

During the combined wind, wave and current test, the mooring cables with similar angle, length and axial stiffness between FSRU and wharf can be simplified into one new cable. Therefore, a total of 10 simplified cables were used to replace 18 cables in the test. Similarly, the 24 connecting cables between FSRU and LNGC were replaced by 10 simplified cables. The attributes of the 20 simplified cables are shown in Table 4. The length and stiffness of each cable are simulated according to the principle of similarity to ensure that the mechanical properties of the model test. The nonlinear spring group and wire rope were used to simulate the mooring and connecting cables. Taking into account the nonlinear characteristics of the fenders, the nonlinear spring groups were used to simulate them. Fig. 6 indicates mechanical property curve of the cables and the nonlinear compression curve of the fenders. In general, the loads on the fender at the bow and stern is larger than those in the middle of the vessels (Newman, 2001). In the experiment, the bearing capacity of the fender is mainly considered. Therefore, in the connection system, pressure sensors are only installed at the four fenders of the vessels at the bow and stern to measure the loads.

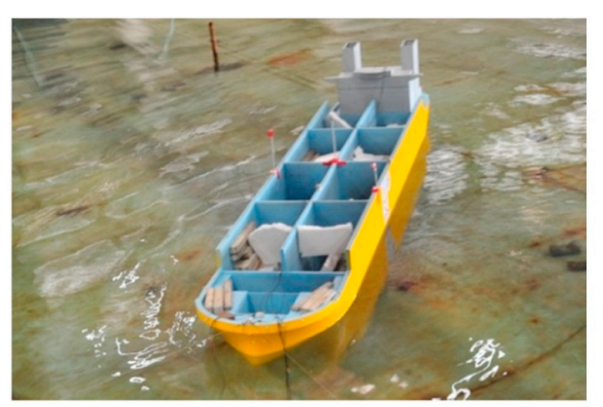

(a)

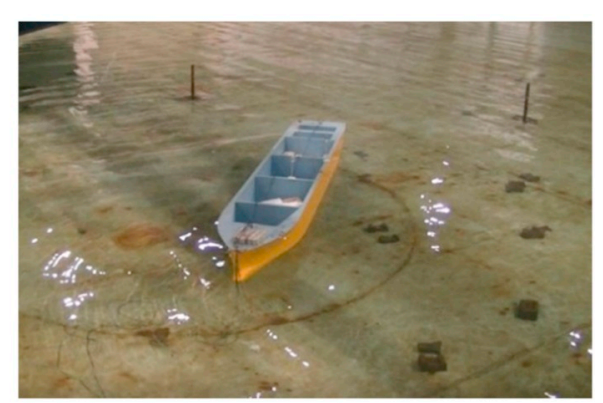

(b)

Fig. 4. Static water attenuation test: (a) shows the full loaded FSRU and (b) shows the ballast LNGC. 


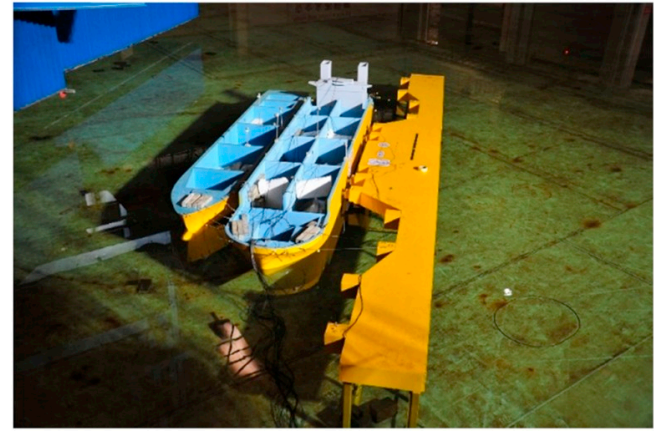

Fig. 5. Combined wind, wave and flow test of the FSRU-LNGC system in the basin.

\section{Results and discussion}

Numerical and experimental study on the dynamic responses of the FSRU-LNGC multi-floating mooring system in side-by-side offloading operation have been carried out. The results include the six degrees of freedom motion of the two vessels, hydrodynamic interactions, the forces on the cables and fenders of the mooring and connecting systems. The numerical results are compared with the experimental results and the results obtained by Zhao (Zhao et al., 2013) to verify the correctness of the numerical calculation.

\subsection{Validation of the numerical results}

Validation process of the numerical results is shown in Fig. 7. Based on the static water attenuation tests, the convergence analysis of the FSRU and LNGC simulation models is executed first. Then the nondimensional damping parameter of the lid used in the side-by-side offloading operation numerical analysis is reasonably selected.

To verify the mesh dependency and convergence, the influences of different meshes on the calculation results are considered at first. From Mesh 1 to Mesh 4, 4537, 6383, 8530 and 10452 panels are adopted on the FSRU-LNGC side-by-side mooring system respectively. The conventional three-dimensional potential theory with zero $\mu$ was used in this part of analyzes. The amplitude response operator (RAO) and added mass in the sway mode for the FSRU of 4 different meshes are shown in Fig. 8. The comparison results show that Mesh 1 has poor mesh quality whose corresponding frequency of peak value is inconsistent with the other meshes, while Mesh 3 and Mesh 4 have better convergence with nearly the same result except for small value discrepancy at the corresponding frequency of peak value. In order to ensure accuracy, Mesh 4 is used for further calculation and analyzes. The mesh used in this paper is generated in the way shown in Fig. 3. The comparison of natural periods of FSRU and LNGC are listed in Table 5. The comparison shows that the
Table 4

Attributes of the 20 simplified cables.

\begin{tabular}{|c|c|c|c|c|}
\hline $\begin{array}{l}\text { Simplified cable } \\
\text { number }\end{array}$ & $\begin{array}{l}\text { Original cable } \\
\text { number }\end{array}$ & $\begin{array}{l}\text { Weight in air } \\
(\mathrm{kg} / \mathrm{m})\end{array}$ & $(\mathrm{kN})$ & Location \\
\hline Line A1 & $1 / 2$ & 2.92 & 3469.2 & $\begin{array}{l}\text { FSRU- } \\
\text { Wharf }\end{array}$ \\
\hline Line A2 & $3 / 4$ & 2.92 & 3469.2 & $\begin{array}{l}\text { FSRU- } \\
\text { Wharf }\end{array}$ \\
\hline Line A3 & 5 & 1.46 & 1734.6 & $\begin{array}{l}\text { FSRU- } \\
\text { Wharf }\end{array}$ \\
\hline Line A4 & $6 / 7$ & 2.92 & 3469.2 & $\begin{array}{l}\text { FSRU- } \\
\text { Wharf }\end{array}$ \\
\hline Line A5 & $8 / 9$ & 2.92 & 3469.2 & $\begin{array}{l}\text { FSRU- } \\
\text { Wharf }\end{array}$ \\
\hline Line A6 & $10 / 11$ & 2.92 & 3469.2 & $\begin{array}{l}\text { FSRU- } \\
\text { Wharf }\end{array}$ \\
\hline Line A7 & $12 / 13$ & 2.92 & 3469.2 & $\begin{array}{l}\text { FSRU- } \\
\text { Wharf }\end{array}$ \\
\hline Line A8 & 14 & 1.46 & 1734.6 & $\begin{array}{l}\text { FSRU- } \\
\text { Wharf }\end{array}$ \\
\hline Line A9 & 15 & 1.46 & 1734.6 & $\begin{array}{l}\text { FSRU- } \\
\text { Wharf }\end{array}$ \\
\hline Line A10 & $16 / 17 / 18$ & 4.38 & 5203.8 & $\begin{array}{l}\text { FSRU- } \\
\text { Wharf }\end{array}$ \\
\hline Line B1 & $41 / 42$ & 1.762 & 2214.8 & $\begin{array}{l}\text { FSRU- } \\
\text { LNGC }\end{array}$ \\
\hline Line B2 & $39 / 40$ & 1.762 & 2214.8 & $\begin{array}{l}\text { FSRU- } \\
\text { LNGC }\end{array}$ \\
\hline Line B3 & $36 / 37 / 38$ & 2.643 & 3322.2 & $\begin{array}{l}\text { FSRU- } \\
\text { LNGC }\end{array}$ \\
\hline Line B4 & $33 / 34 / 35$ & 2.643 & 3322.2 & $\begin{array}{l}\text { FSRU- } \\
\text { LNGC }\end{array}$ \\
\hline Line B5 & $31 / 32$ & 1.762 & 2214.8 & $\begin{array}{l}\text { FSRU- } \\
\text { LNGC }\end{array}$ \\
\hline Line B6 & $29 / 30$ & 1.762 & 2214.8 & $\begin{array}{l}\text { FSRU- } \\
\text { LNGC }\end{array}$ \\
\hline Line B7 & $26 / 27 / 28$ & 2.643 & 3322.2 & $\begin{array}{l}\text { FSRU- } \\
\text { LNGC }\end{array}$ \\
\hline Line B8 & $23 / 24 / 25$ & 2.643 & 3322.2 & $\begin{array}{l}\text { FSRU- } \\
\text { LNGC }\end{array}$ \\
\hline Line B9 & $21 / 22$ & 1.762 & 2214.8 & $\begin{array}{l}\text { FSRU- } \\
\text { LNGC }\end{array}$ \\
\hline Line B10 & $19 / 20$ & 1.762 & 2214.8 & $\begin{array}{l}\text { FSRU- } \\
\text { LNGC }\end{array}$ \\
\hline
\end{tabular}

natural periods of the two vessels obtained from the model test and simulations are in good agreement. This also illustrates that 3589 elements for FSRU, 2743 elements for LNGC and 4119 elements for the wharf are enough to make the numerical simulation converge.

As can be seen from Fig. 8, there are peak values in some frequency ranges that are not consistent with the actual situation. This may be caused by irregular frequency and harmonic resonance. In the process of using the panel method, with the increase of the frequency of hydrodynamic calculation, the irregular frequency will appear successively. The influence of irregular frequency on the calculated results can be

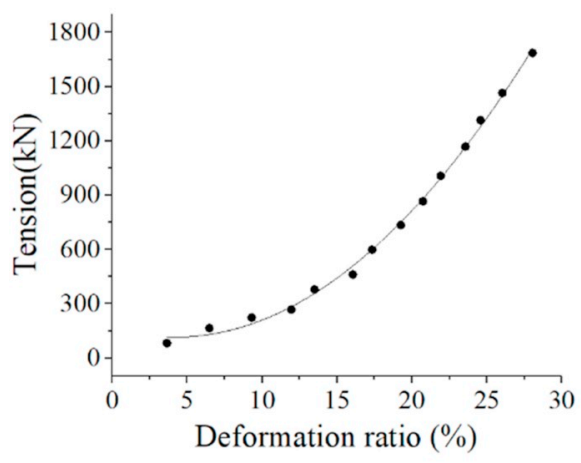

(a)

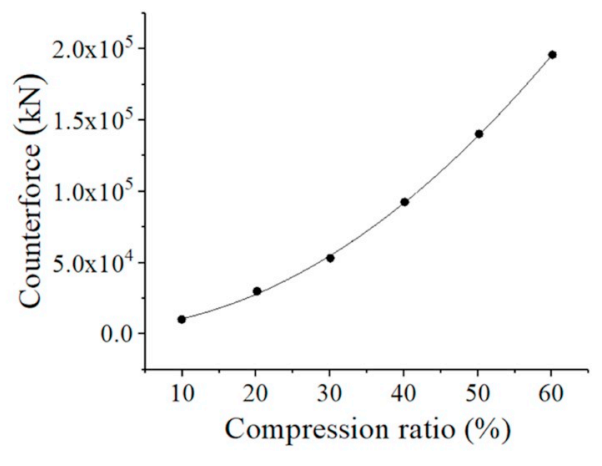

(b)

Fig. 6. Mechanical property curves: (a) shows the cables and (b) shows the fenders. 


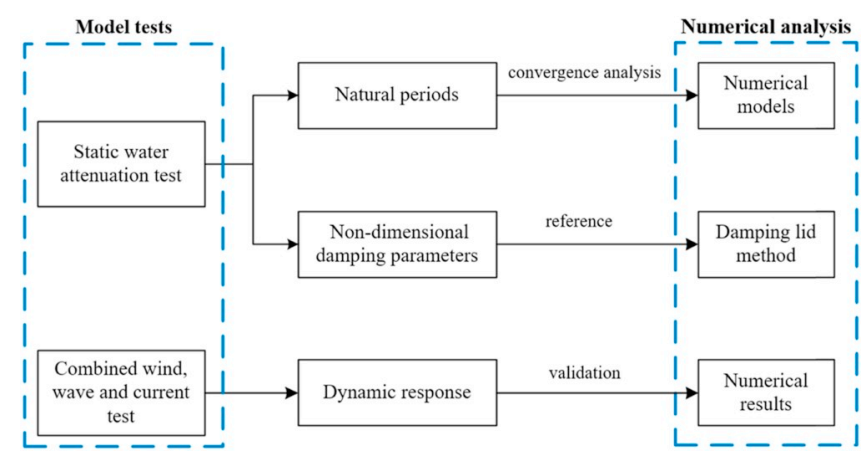

Fig. 7. Validation process of the numerical results.

reduced by increasing the number of model elements, but it cannot be eliminated fundamentally (Journee and Massie, 2001). In order to remove the irregular frequency, Teng (Teng and Li, 1996) proposed a method of applying artificial lid on the inner water surface of the floating body, but the results show that their method does not eliminate irregular frequency completely, but pushes irregular frequency towards high frequency. Using the integral equation of simple Green's function (Yeung, 1975) or the mixed element method (Bai, 1972) will not lead to irregular frequency problems. However, their calculation amount will be greatly increased. Sun (Sun et al., 2008a, 2008b) proposed a new method based on the extended integral region, which effectively removes the irregular frequency in the calculation results of the two ships that are simplified to the fixed square box. However, its effectiveness in the multi-floating side-by-side mooring system without simplification still needs to be verified.

When waves of certain frequency acts on two side-by-side floating bodies with small gaps, a large wave height will appear at the gap (Sun et al., 2008a, 2008b). In the case of resonance, viscosity and energy dissipation of the fluid cannot be considered by using the three-dimensional potential flow theory. The hydrodynamic parameters of the floating bodies and the wave surface rise value obtained by the calculation are too large, resulting in obvious distortion (Xin et al., 2014). In order to reduce the resonance peak value and make the calculation result closer to the real situation, this part mainly discusses the correction of the calculation result of potential flow. The damping lid method based on the assumption of quasi-ideal fluid is used to add damping on the free water surface between two ships, and the correction of frequency-domain calculation result can be achieved by selecting the appropriate non-dimensional damping parameter. The damping lid method was introduced in detail by Chen (2004) and the sensitivity of the results for this method was presented by Chen (Chen and Malenica, 2005) and Chakrabarti (1978).

Therefore, this paper only adopts the method of increasing the
Table 5

Comparison between experimental data and simulations of the natural periods.

\begin{tabular}{llllll}
\hline \multirow{2}{*}{ Item } & \multicolumn{2}{l}{ Experimental natural periods (s) } & & \multicolumn{2}{l}{ Numerical natural periods (s) } \\
\cline { 2 - 3 } \cline { 6 - 6 } \cline { 5 - 6 } & Roll & Pitch & & Roll & Pitch \\
\hline FSRU (full) & 13.2 & 9.784 & & 13.34 & 9.84 \\
LNGC (ballast) & 11.9 & 9 & & 11.84 & 9.03 \\
\hline
\end{tabular}

Table 6

Non-dimensional damping parameters obtained from the experiment.

\begin{tabular}{lll}
\hline \multirow{2}{*}{ Item } & \multicolumn{2}{l}{ Experimental non-dimensional damping parameters } \\
\cline { 2 - 3 } & Roll & Pitch \\
\hline FSRU (full) & 0.01 & 0.422 \\
LNGC (ballast) & 0.016 & 0.239 \\
\hline
\end{tabular}

number of elements to minimize the impact of irregular frequency on the calculation results. On this basis, the damping lid method is used to modify the frequency-domain calculation results to obtain a more accurate dynamic response of the multi-floating side-by-side mooring system. The dependence and convergence analysis of the mesh is shown in Fig. 8 and Mesh 4 is selected for further calculation. On this basis, the numerical calculation based on the potential flow theory is revised mainly through the way of the damping lid method. Referring to the roll and pitch non-dimensional damping parameters listed in Table 6 and through the frequency-domain calculation, the non-dimensional damping parameter of the lid used in the numerical calculation is chosen as 0.018. Fig. 9 shows the effects of the damping lid method on frequencydomain calculation results of FSRU. It can be observed that adding the damping lid to the free surface between two ships can effectively reduce the excessive peak value in the potential flow calculation at the resonance frequency. The damping lid method simulates the viscous effect of fluid resonance by adding damping on the free surface between the two vessels. It can make the numerical results closer to the real dynamic responses.

Both numerical and experimental analysis of the FSRU-LNGC system are performed under the combined wind, wave and current. The oblique sea waves will induce both transverse and longitudinal motions of the vessels. However, it can be observed from the model tests that the surge and roll motions dominate FSRU-LNGC multi-floating mooring system responses compared to the motions in other degrees of freedom. Thus the results of surge and roll motion responses are showed to demonstrate the dynamic response of the FSRU-LNGC system. Furthermore, the results of the cable 5 which is subjected to the largest forces in the mooring system are introduced in detail. In the experiment, the simplified cables of the connecting system all represent two or three original cables and

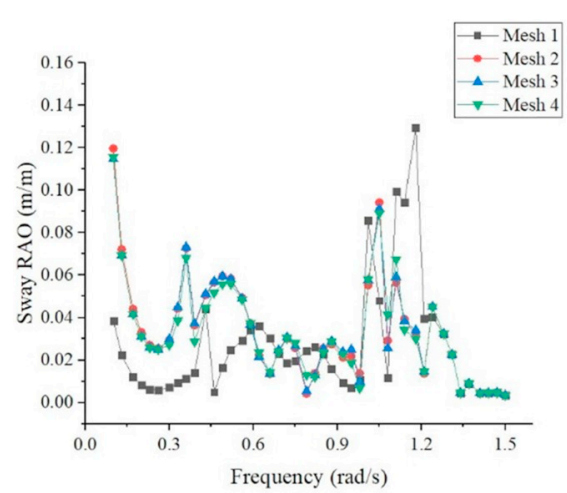

(a) Sway RAO

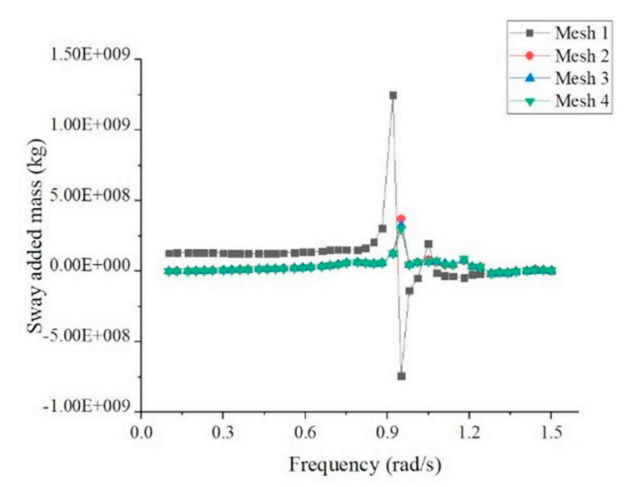

(b) Sway added mass

Fig. 8. Effects of different meshes on sway RAO and sway added mass of FSRU. (a) Sway RAO (b) Sway added mass. 


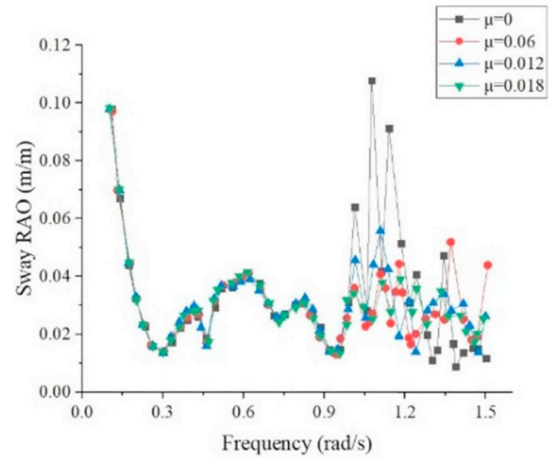

(a) Sway RAO

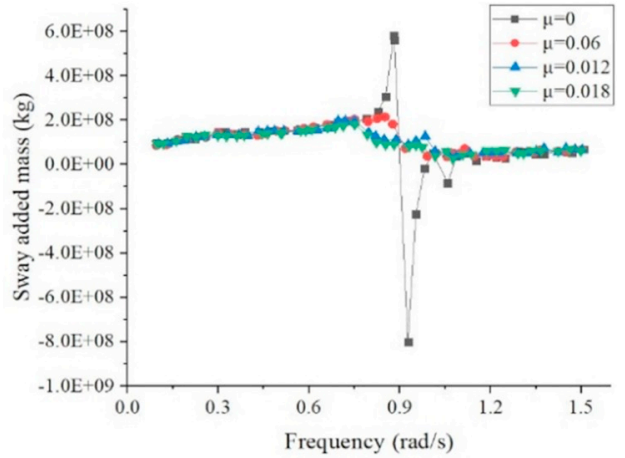

(b) Sway added mass

Fig. 9. Effects of damping lid method on frequency-domain calculation results of FSRU.

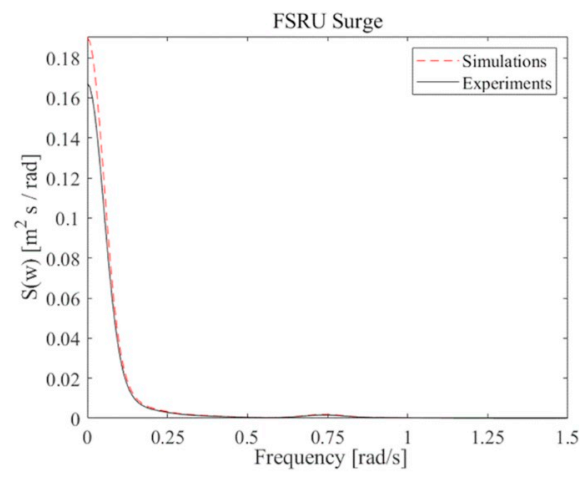

(a)

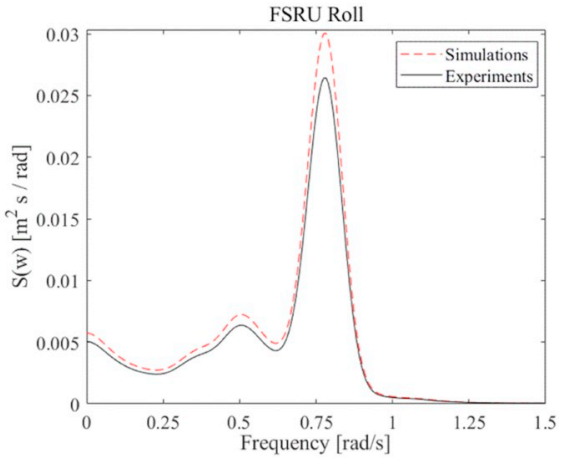

(b)

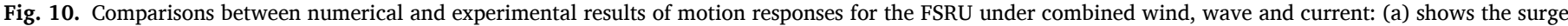
motions and (b) shows the roll motions.

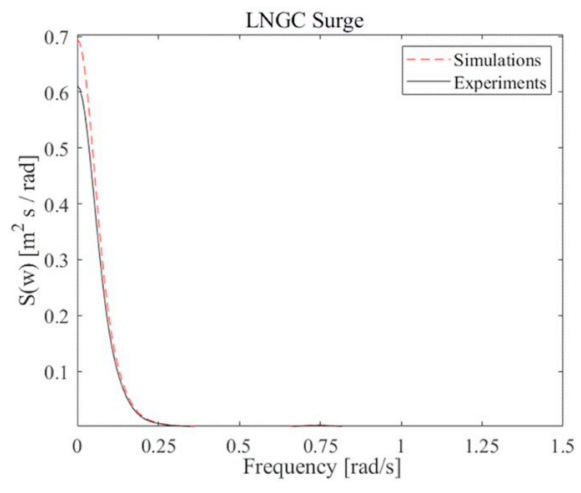

(a)

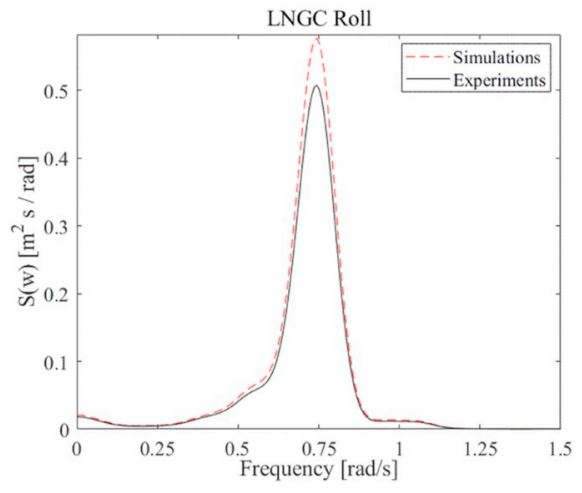

(b)

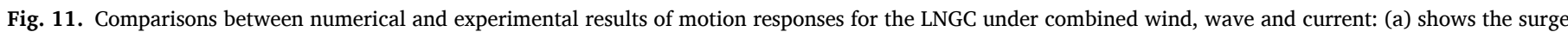
motions and (b) shows the roll motions.

the forces of the original single connecting cable cannot be measured. Therefore, only the comparison of the most stressed cable group is given. Comparisons between the numerical and experimental results are presented by response spectrums.

The numerical and experimental comparisons for the FSRU and LNGC are presented in Fig. 10 and Fig. 11, respectively. It is shown that the surge and roll motion responses obtained by numerical analysis are in good agreement with the test results. The variation trend and peak frequency of response spectrums of surge and roll motions are consistent with the results of Zhao (Zhao et al., 2013). It can be seen from the response spectrums that the surge motions of the two vessels concentrate on low frequencies, while the peak frequency of the roll motions is located in the $0.75 \mathrm{rad} / \mathrm{s}$, close to the natural frequencies of the two vessels. However, small discrepancies can be observed between the numerical and experimental results as listed in Table 7. In general, the surge and roll motions for both the FSRU and LNGC estimated by the numerical analysis are a little bit larger than the test results. This may be caused by the fact that in the numerical analysis, the damping lid method (Fig. 3) adds a linear damping term in free surface, but the actual natural damping should be nonlinear. 
Table 7

Comparison between numerical and experimental statistics.

\begin{tabular}{llllll}
\hline Item & & Max. & Min. & Mean & Std. \\
\hline FSRU Surge (m) & Experiments & 0.24 & 0.72 & 0.14 & 0.11 \\
& Simulations & 0.29 & 0.67 & 0.07 & 0.12 \\
FSRU Roll (deg) & Experiments & 0.37 & 0.51 & 0.05 & 0.08 \\
& Simulations & 0.38 & 0.50 & 0.03 & 0.08 \\
LNGC Surge (m) & Experiments & 0.18 & 1.52 & 0.39 & 0.22 \\
& Simulations & 0.22 & 1.57 & 0.42 & 0.24 \\
LNGC Roll (deg) & Experiments & 1.45 & 1.36 & 0.03 & 0.30 \\
& Simulations & 1.50 & 1.32 & 0.09 & 0.30 \\
Line A3/Cable 5 (kN) & Experiments & 481.91 & 112.60 & 187.89 & 39.08 \\
& Simulations & 445.22 & 117.60 & 192.29 & 37.46 \\
Line B7/Cables 26/27/ & Experiments & 1588.19 & 18.90 & 582.22 & 199.64 \\
28 (kN) & Simulations & 1600.79 & 0.13 & 492.74 & 209.59 \\
\hline
\end{tabular}

Comparisons of the forces estimated from the numerical analysis and experimental tests are presented in Fig. 12 for the cable 5 in mooring system (left plot) and the cable group consists of cables $26 / 27 / 28$ in connecting system (right plot). The forces estimated by the numerical analysis are well consistent with measurements from the tests. It can be known from Fig. 12 that the dynamic tension of cable 5 in the mooring system mainly occurs in the low frequencies similar as the surge and roll motions of the FSRU in Fig. 10. The dynamic tension of cables 26/27/28 mainly occurs around the wave frequencies also similar as the roll motions of FSRU and LNGC. As can be seen in Table 7, there are small discrepancies of the statistical motion and force responses between the numerical analysis and the experimental tests. Both the motion and force responses obtained from the numerical analysis are larger than that of the experiments. The discrepancies might be caused by that the numerical analysis uses the original 42 cables from the original mooring design, while in the experiment test these 42 cables are simply replaced by 20 cables as shown in Table 4 .

In general, the numerical analysis and experimental tests show satisfactory agreement. The numerical calculation method and model tests used in this study are feasible, and the damping coefficient selected based on experimental data is reasonable.

\subsection{Dynamic responses of FSRU-LNGC side-by-side mooring system}

Based on the numerical model and the damping parameters that are validated above, the dynamic responses of the FSRU-LNGC side-by-side mooring system under the specific sea condition are analyzed in this section. The investigation of the response characteristics can be also used in the collision analysis between the two floating bodies.

\subsubsection{Ship motions in six degrees of freedom}

In order to analyze the motion characteristics of the side-by-side moored FSRU and LNGC under combined wind, wave and current, the time series of the six degrees of freedom motion responses of the two vessels from the proposed numerical analysis are shown in Fig. 13. Some basic statistics of the time series responses are listed in Table 8.

As can be seen in Fig. 13, motion responses on the LNGC are in general larger than on the FSRU, especially in surge, sway and roll motions. Moreover, the amplitude of the surge responses of the LNGC is much larger than that of FSRU as shown in Table 8. For the comparision of the roll motion, it is obvious that the amplitude of the motion response of the FSRU is so small that it can be negligible. This may be related to the big differences of principal dimensions between the two floating vessels. The principal dimensions of FSRU are much larger than those of LNGC. Furthermore, the FSRU is designed as a floating structure with larger block coefficient and displacement (also inducing large added mass) than LNGC. Thus, there is a smaller motion response on FSRU than LNGC under the same sea condition. According to Fig. 13, it can be observed that the response frequencies of six degrees of freedom are quite different. The response frequency of surge motion is the lowest compared with other motion modes such as sway, heave and roll. This can be explained by the effect of the cables in both mooring system and connecting system, which can increase the response period of surge motion and reduce its response frequency.

\subsubsection{Relative motion}

During the side-by-side offloading operation, the FSRU and LNGC are close to each other and are prone to collision. Furthermore, the relative motion of the two ships has a great influence on the force acting on the cables and fenders of the connecting system. In order to ensure the operational safety of the cables and fenders, the relative motion between the two ships should be seriously investigated. Additionally, heave, roll and pitch motions have a great impact on the safety performance of sideby-side offloading operation, and they should be carefully analyzed as well. Therefore, on the premise of analyzing the six degrees of freedom motion of FSRU and LNGC respectively, the relative heave, roll and pitch motions between the two vessels are investigated with FSRU as the reference object.

Fig. 14 presents the relative heave, roll and pitch motions between the FSRU and LNGC. According to Fig. 14, the amplitude of the relative heave and pitch motions is similar and that of the relative roll motion is twice as large. This indicates that the relative roll motion between the two vessels is much more important than the relative heave and pitch motions. However, the relative motion response frequencies in three directions are similar. The similar phenomenon could be found when the motion responses of FSRU and LNGC are analyzed separately. Through the relative heave, roll and pitch motions analysis of the two vessels, it can be concluded that relative roll motion dominates the dynamic responses of the connecting system between two vessels under the given

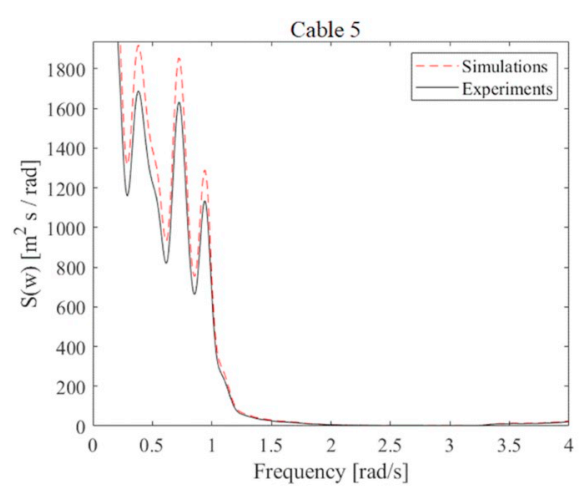

(a)

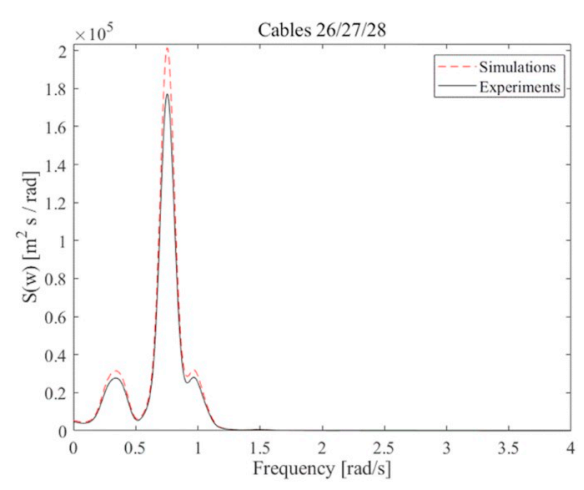

(b)

Fig. 12. Comparisons between numerical and experimental results of the forces on the cables under combined wind, wave and current: (a) shows the cable 5 and (b) shows the cables $26 / 27 / 28$. 


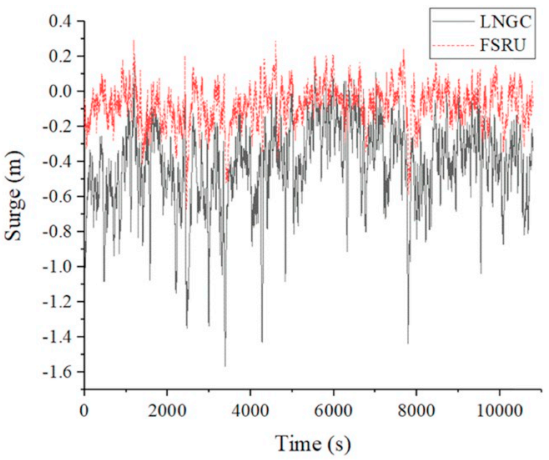

(a) surge

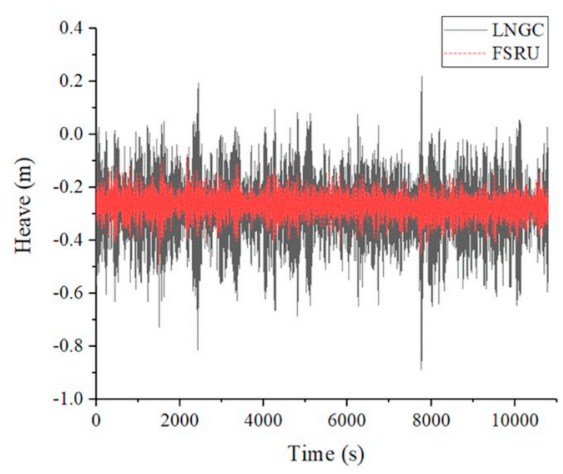

(c) heave

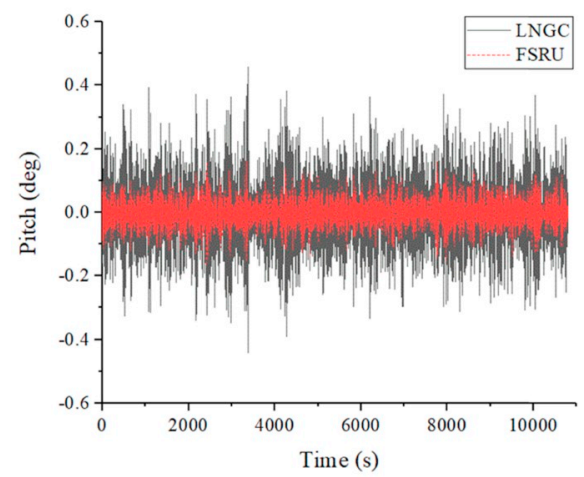

(e) pitch

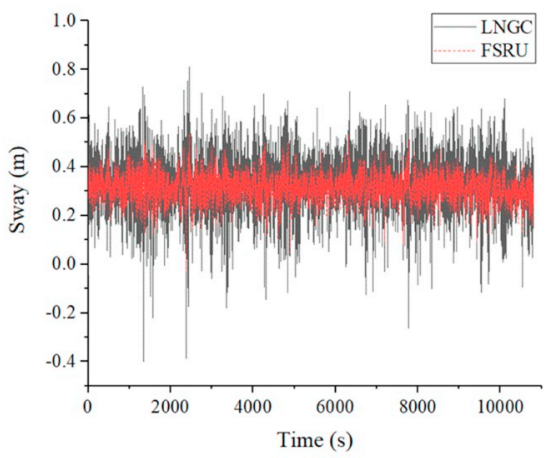

(b) sway

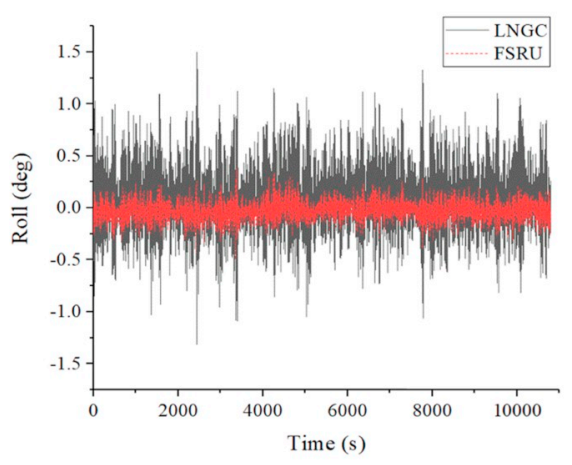

(d) roll

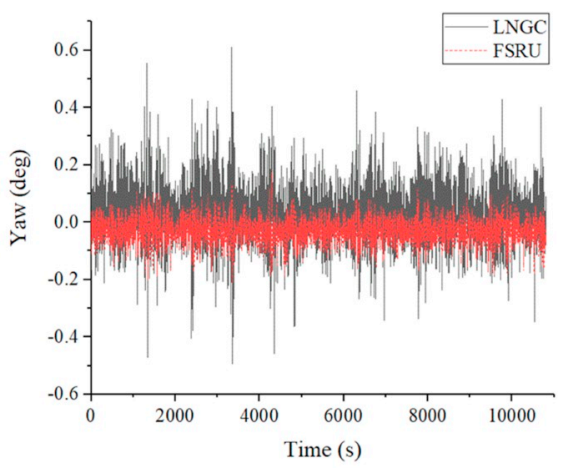

(f) yaw

Fig. 13. Time series of the six degrees of freedom motions of the FSRU and LNGC.

Table 8

Summery of motion statistics of the FSRU and LNGC.

\begin{tabular}{llcccc}
\hline Item & & Max. & Min. & Mean & Std. \\
\hline Surge(m) & LNGC & 0.22 & 1.57 & 0.42 & 0.24 \\
& FSRU & 0.29 & 0.67 & 0.07 & 0.12 \\
Sway(m) & LNGC & 0.81 & 0.40 & 0.32 & 0.12 \\
& FSRU & 0.54 & 0.03 & 0.31 & 0.05 \\
Heave(m) & LNGC & 0.22 & 0.89 & 0.28 & 0.12 \\
& FSRU & 0.09 & 0.49 & 0.27 & 0.04 \\
Roll(deg) & LNGC & 1.50 & 1.32 & 0.09 & 0.30 \\
& FSRU & 0.38 & 0.50 & 0.03 & 0.08 \\
Pitch(deg) & LNGC & 0.46 & 0.44 & 0.00 & 0.10 \\
& FSRU & 0.16 & 0.17 & 0.00 & 0.04 \\
Yaw(deg) & LNGC & 0.61 & 0.49 & 0.03 & 0.10 \\
& FSRU & 0.18 & 0.21 & 0.03 & 0.04 \\
\hline
\end{tabular}

sea condition.

\subsubsection{Cables and fenders}

The FSRU-LNGC multi-floating mooring system contains multiple cables and fenders. The maximum force acting on the cables and fenders is of great significance to the safety of side-by-side offloading operation. The side-by-side configuration of the multi-floating mooring system is described in detail in Fig. 1. The FSRU-wharf mooring system consists of 18 cables and 4 fenders, of which from the bow to the stern the cable number is \#1 \#18 and the fender number is \#43 \#46. Similarly, the FSRU-LNGC connecting system consists of 24 cables and 8 fenders, of which from bow to stern the cable number is \#42 \#19 and the fender number is \#54 \#53. Fig. 15 and Fig. 16 show the statistics of maximum cable tension and maximum fender forces under the combined wind, wave and current loads, respectively.

Fig. 15 shows that the cables arranged in different positions bear different forces, and those placed in similar locations experience similar loads. This can be explained by its similar angles, length and stiffness. 


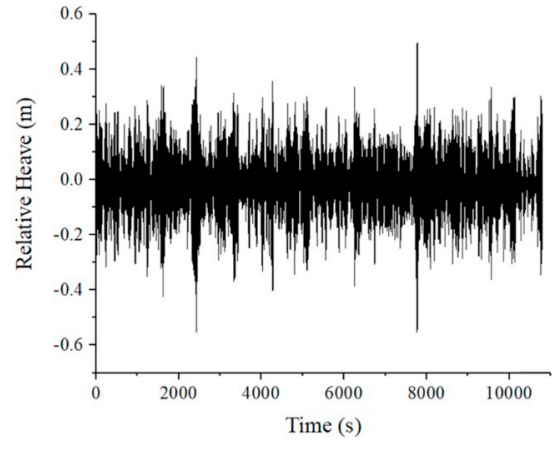

(a) relative heave

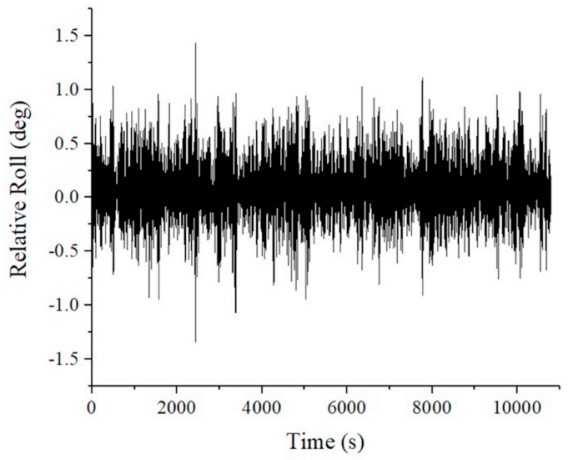

(b) relative roll

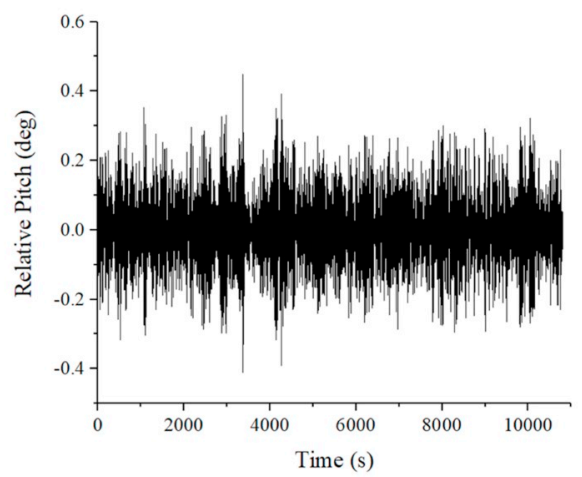

(c) relative pitch

Fig. 14. Time series of the relative motions between FSRU and LNGC.

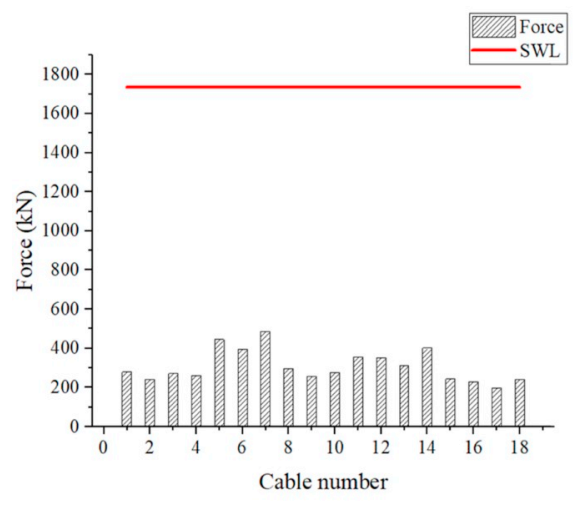

(a)

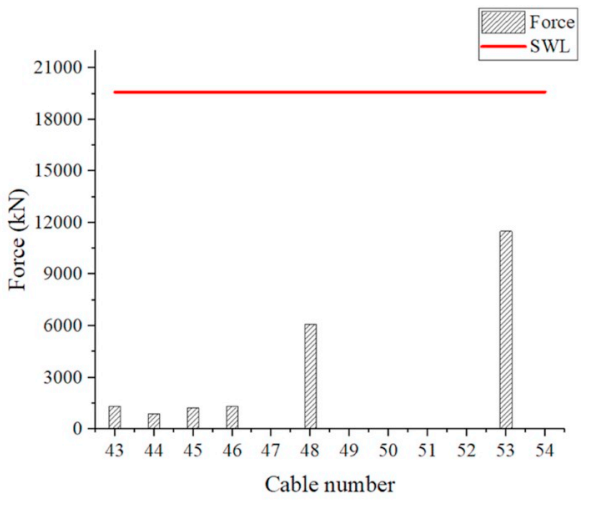

(b)

Fig. 15. Maximum tension statistics of cables: (a) shows the cables in mooring system and (b) shows the cables in connecting system.

The maximum force of the connecting cable is $529.4 \mathrm{kN}$ and that of the mooring cable is $445.22 \mathrm{kN}$. The maximum force of the connecting cable is greater than that of the mooring cable, which is consistent with the results shown by Zhao (Zhao et al., 2013). This may be due to the severe relative motion between the two vessels. However, the largest forces acting on both mooring cables and connecting cables are much smaller than their SWL under the given sea state. The safety margin of the cable allows the FSRU-LNGC side-by-side mooring system to operate safely in worse sea conditions.

According to Fig. 16, it is obvious that the difference of estimated forces among the fenders of the mooring system is small, while that in the connecting system is large. In the connecting system, the force acting on the fender 53 in the bow is much larger than the fender 48 in the stern, while other fender forces are negligible compared to them. The maximum force acting on the fenders of connecting system and mooring system are $11400.2 \mathrm{kN}$ and $1300 \mathrm{kN}$, respectively. They are smaller than their SWL. The maximum force acting on the fenders of connecting system is much larger than that of mooring system. This may be due to the complex interaction of hydrodynamic force and relative motions between FSRU and LNGC. For a more specific analysis of the fender forces in the connection system, Fig. 17 shows the time series of the fenders with large force at bow and stern in the connection system, respectively. There are many intervals in the time series of the forces acting on fenders, and the number of intervals occurring at the bow is larger than at the stern. This illustrates that there are many collisions between the bow and stern of two ships, and the fender at the bow experiences more collisions than the fender at the stern. 


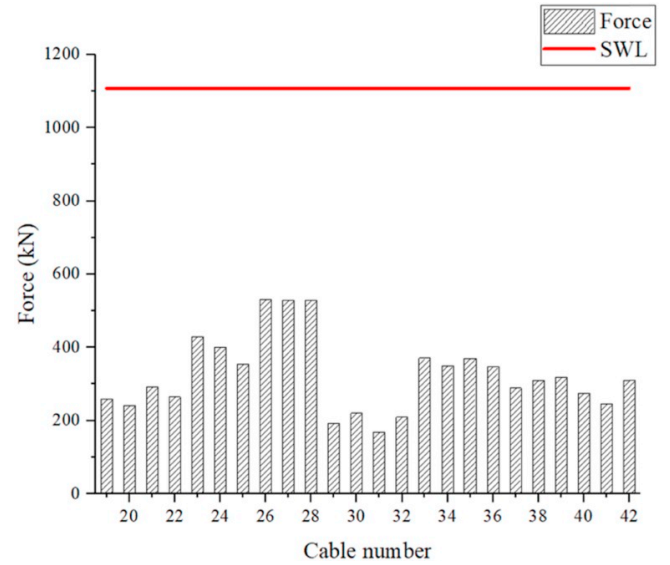

Fig. 16. Maximum force statistics of fenders in the FSRU-LNGC system.

\section{Sensitive analysis}

Due to the complex hydrodynamic interaction between the two vessels, the pretension of the connecting cables has a great influence on the dynamic responses of the mooring system. The sensitivity analysis of the pretension of the connecting cables is of great significance to the safety performance of the side-by-side offloading operation. Based on the analysis of the dynamic responses of the FSRU-LNGC side-by-side mooring system, the sensitivity study focuses on the investigation of the connecting cable pretension on the six degrees of freedom motion, relative motions, cable tension and fender forces of the two floating bodies are presented.

According to the guidelines (OCIMF, 2008), each cable of the system should maintain the same pretension, typically taking $10 \%$ of its breaking force. This is easy to implement for a symmetrical arrangement such as the single point mooring. However, the multi-floating mooring system in this paper adopts wharf mooring, and the side-by-side arrangement is not completely symmetrical, so it is difficult to achieve the same pretension of 24 cables. Therefore, the pretension is changed by changing the length of the connecting cables, and a certain proportion is added to the original cable length. As the length of the connecting cables increases, the pretension decreases. The cases selected for the sensitivity study are listed in Table 9. The other parameters not listed in Table 9 keep the same as in the base case.

\subsection{Effects on the ship motions in six degrees of freedom}

For the motion response analysis of the vessels, besides the maximum value of motion, the amplitude of motion also needs to be investigated, because it can reflect the range of motion of the ship on a certain degree

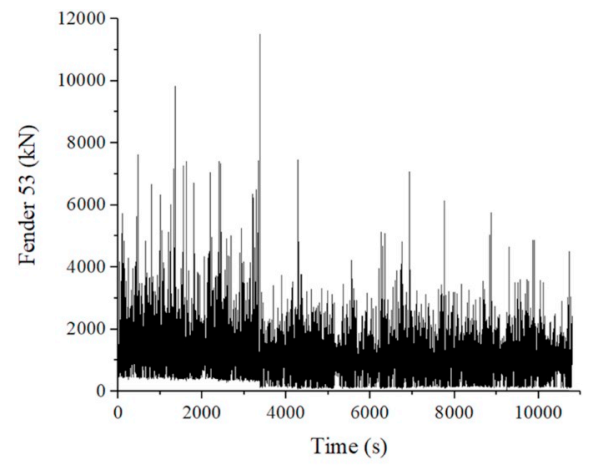

(a) of freedom. It can be observed from Table 10 that the motion responses can be significantly affected by the pretension of the connecting cables. Both the maximum value and the amplitude of LNGC and FSRU motion responses increase as the pretension of the connecting cables decrease. One can also concluded from Table 10 that the influence of the connecting cables pretension on the motion amplitude of the vessels is nonlinear. The motion response of LNGC is much more sensitive than that of FSRU to the pretension of the connecting cables. When the length of the connecting cables increases from $2 \%$ to $3 \%$, the roll motion of the two floating bodies significantly changes, which indicates that when the connecting cable length is within this range, increasing the pretension of the connecting cables can significantly improve the roll motion characteristics of the two floating bodies. The large-amplitude roll motion of the vessels will affect the normal life of the crew and the safety performance of the side-by-side offloading operation of the system. The vessel will exhibit complex nonlinear dynamic behavior under largeamplitude roll motion. Serious large-amplitude roll motion can cause the vessel to capsize under the wave excitation or other excitation disturbance. The severe roll motion of the two floating bodies in the multi-floating mooring system can be improved by increasing the pretension of the connecting cables. Furthermore, the heave, roll and pitch motions are more sensitive than that of the other degrees of freedom. Therefore, based on the analysis of the influence of the pretension of the connecting cables on the six degrees of freedom motion response of the two ships, the sensitivity analysis of relative heave, roll and pitch between the two ships are carried out.

\subsection{Effects on the relative motions}

Fig. 18 shows the time series of the relative heave, roll and pitch motions between the FSRU and LNGC. It can be observed from the figure that the relative heave, roll and pitch motions increase as the pretension of the connecting cables decrease. In order to make quantitative analysis, the statistics of the relative motions are illustrated in Table 11. As shown in Table 11, the decrease of the pretension on the connecting cables can lead to nonlinearly increase of both the maximum values and amplitudes of the relative motions. The relative motions of the case 1 do not differ too much from that of the case 2 , but obvious difference can be found from the case 2 to the case 3 . Similar to the effect of the pretension

Table 9

Sensitivity cases configurations.

\begin{tabular}{llc}
\hline Case & Connecting cable number & Proportion \\
\hline Case 1 & $\# 19-\# 42$ & $1 \%$ \\
Case 2 & $\# 19-\# 42$ & $2 \%$ \\
Case 3 & $\# 19-\# 42$ & $3 \%$ \\
Base case & $\# 19-\# 42$ & 0 \\
\hline
\end{tabular}

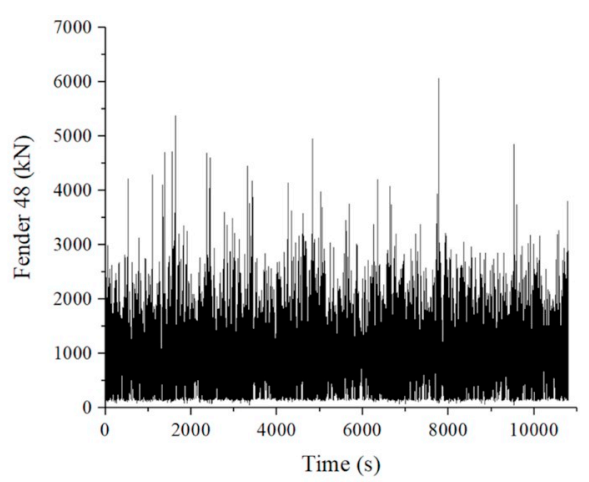

(b)

Fig. 17. Time series of the fenders with maximum force in connecting system: (a) shows fender 53 at stern and (b) shows fender 48 at bow. 
Table 10

Summary of the motion statistic in different pretension cases.

\begin{tabular}{|c|c|c|c|c|c|c|c|c|c|}
\hline \multirow[t]{2}{*}{ Item } & \multirow[t]{2}{*}{ Case } & \multicolumn{2}{|l|}{ Max. } & \multicolumn{2}{|l|}{ Min. } & \multicolumn{2}{|l|}{ Mean } & \multicolumn{2}{|c|}{ Amplitude } \\
\hline & & LNGC & FSRU & LNGC & FSRU & LNGC & FSRU & LNGC & FSRU \\
\hline \multirow[t]{3}{*}{ Surge(m) } & Case 1 & 0.24 & 0.31 & 1.50 & 0.67 & 0.40 & 0.08 & 1.74 & 0.98 \\
\hline & Case 2 & 0.25 & 0.35 & 1.59 & 0.69 & 0.38 & 0.08 & 1.84 & 1.04 \\
\hline & Case 3 & 0.42 & 0.36 & 1.62 & 0.72 & 0.41 & 0.09 & 2.04 & 1.08 \\
\hline \multirow[t]{3}{*}{ Sway(m) } & Case 1 & 0.83 & 0.56 & 0.20 & 0.03 & 0.30 & 0.29 & 1.03 & 0.59 \\
\hline & Case 2 & 0.85 & 0.62 & 0.30 & 0.01 & 0.32 & 0.36 & 1.15 & 0.61 \\
\hline & Case 3 & 1.12 & 0.55 & 0.26 & 0.08 & 0.36 & 0.33 & 1.38 & 0.63 \\
\hline \multirow[t]{3}{*}{ Heave(m) } & Case 1 & 0.22 & 0.09 & 0.87 & 0.5 & 0.25 & 0.28 & 1.09 & 0.41 \\
\hline & Case 2 & 0.32 & 0.06 & 0.86 & 0.56 & 0.31 & 0.25 & 1.18 & 0.50 \\
\hline & Case 3 & 1.92 & 0.89 & 0.99 & 0.64 & 0.27 & 0.22 & 2.91 & 1.53 \\
\hline \multirow[t]{3}{*}{ Roll(deg) } & Case 1 & 1.56 & 0.41 & 1.23 & 0.54 & 0.10 & 0.05 & 2.79 & 0.95 \\
\hline & Case 2 & 1.75 & 0.45 & 0.85 & 0.62 & 0.42 & 0.12 & 2.60 & 1.07 \\
\hline & Case 3 & 7.43 & 1.03 & 6.84 & 1.8 & 0.06 & 1.31 & 14.27 & 2.83 \\
\hline \multirow[t]{3}{*}{ Pitch(deg) } & Case 1 & 0.46 & 0.18 & 0.42 & 0.19 & 0.00 & 0.02 & 0.88 & 0.37 \\
\hline & Case 2 & 0.48 & 0.18 & 0.45 & 0.23 & 0.02 & 0.01 & 0.93 & 0.41 \\
\hline & Case 3 & 0.52 & 0.20 & 0.52 & 0.34 & 0.01 & 0.00 & 1.04 & 0.54 \\
\hline \multirow[t]{3}{*}{ Yaw(deg) } & Case 1 & 0.62 & 0.21 & 0.48 & 0.21 & 0.02 & 0.01 & 1.10 & 0.42 \\
\hline & Case 2 & 0.62 & 0.24 & 0.53 & 0.19 & 0.00 & 0.01 & 1.15 & 0.43 \\
\hline & Case 3 & 0.69 & 0.28 & 0.55 & 0.15 & 0.01 & 0.02 & 1.24 & 0.43 \\
\hline
\end{tabular}

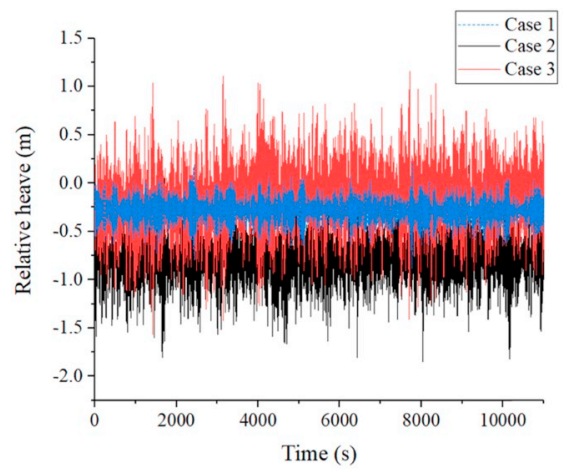

(a)

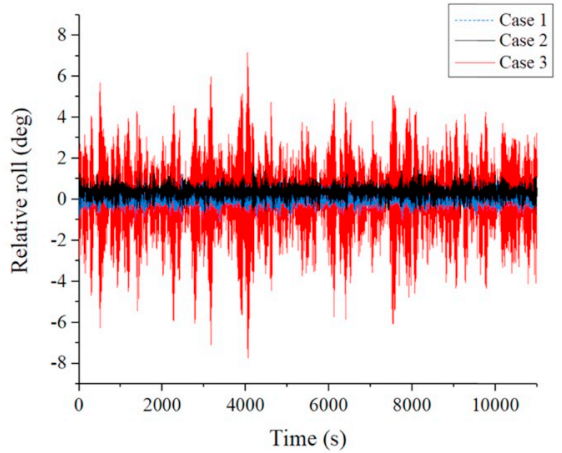

(b)

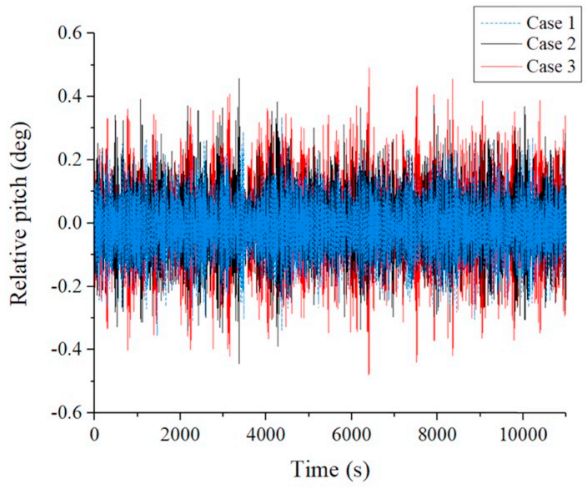

(c)

Fig. 18. Time series of the relative motions between FSRU and LNGC in different pretension conditions.

of the connecting cables on ship motions in six degrees of freedom, when the length of the connecting cable is increased from $2 \%$ to $3 \%$, the relative motions of the two floating bodies obviously increases, especially the relative roll motion. This indicates that increasing the pretension of the connecting cables can significantly improve the relative motion characteristics between the two floating bodies when the length of the connecting cable is within this range. The severe relative roll motion between the two floating bodies in the multi-floating system can be improved by increasing the pretension of the connecting cables. The standard deviations of the relative heave, roll and pitch motions increase as the pretension decrease. It means that decrease of the pretension of the connecting cables would induce severer relative motions between the floating vessels. Furthermore, it can be seen from Table 11 that the relative heave and roll are much more sensitive than that of the relative pitch.

\subsection{Effects on the forces acting on the cables and fenders}

Table 12 shows the maximum forces acting on the representative cables and fenders in both the mooring system and the connecting system under different pretension conditions. As shown in the table, the most stressed cable in the mooring system has always been cable \#5, 
Table 11

Summary of the relative motion statistic in different pretension cases.

\begin{tabular}{lllcccl}
\hline Item & Case & Max. & Min. & Mean & Std. & Amplitude \\
\hline Relative heave(m) & Case 1 & 0.22 & 0.89 & 0.29 & 0.12 & 1.11 \\
& Case 2 & 0.27 & 1.55 & 0.78 & 0.25 & 1.82 \\
& Case 3 & 1.20 & 1.57 & 0.17 & 0.33 & 2.77 \\
Relative roll(deg) & Case 1 & 1.45 & 1.36 & 0.03 & 0.29 & 2.81 \\
& Case 2 & 1.68 & 0.82 & 0.37 & 0.33 & 2.52 \\
& Case 3 & 7.17 & 7.74 & 0.01 & 1.63 & 14.91 \\
Relative pitch(deg) & Case 1 & 0.40 & 0.41 & 0.01 & 0.08 & 0.81 \\
& Case 2 & 0.45 & 0.4 & 0.00 & 0.10 & 0.85 \\
& Case 3 & 0.49 & 0.48 & 0.00 & 0.12 & 0.97 \\
\hline
\end{tabular}

Table 12

Summary of the statistics of the forces in different pretension cases.

\begin{tabular}{|c|c|c|c|c|c|c|}
\hline Item & Case & $\begin{array}{l}\text { cable } \\
\text { number }\end{array}$ & Max. & Min. & Mean & Std. \\
\hline \multirow[t]{3}{*}{$\begin{array}{l}\text { Mooring cable } \\
\quad(\mathrm{kN})\end{array}$} & $\begin{array}{l}\text { Case } \\
1\end{array}$ & \#5 & 452.32 & 110.34 & 183.42 & 38.25 \\
\hline & $\begin{array}{l}\text { Case } \\
2\end{array}$ & $\# 5$ & 466.8 & 121.67 & 198.71 & 45.27 \\
\hline & $\begin{array}{l}\text { Case } \\
3\end{array}$ & $\# 5$ & 472.21 & 118.4 & 120.56 & 60.32 \\
\hline \multirow[t]{3}{*}{$\begin{array}{l}\text { Mooring } \\
\text { fenders }(\mathrm{kN})\end{array}$} & $\begin{array}{l}\text { Case } \\
1\end{array}$ & $\# 46$ & 1308.41 & 5.62 & 202.92 & 202.68 \\
\hline & $\begin{array}{l}\text { Case } \\
2\end{array}$ & $\# 46$ & 1321.23 & 6.81 & 204.83 & 200.19 \\
\hline & $\begin{array}{l}\text { Case } \\
3\end{array}$ & \#46 & 1352.89 & 7.99 & 208.72 & 189.72 \\
\hline \multirow[t]{3}{*}{$\begin{array}{l}\text { Connecting } \\
\text { cables }(\mathrm{kN})\end{array}$} & $\begin{array}{l}\text { Case } \\
1\end{array}$ & \#26 & 570.1 & 8.94 & 200.49 & 150.1 \\
\hline & $\begin{array}{l}\text { Case } \\
2\end{array}$ & $\# 24$ & 624.43 & 14.61 & 208.51 & 149.62 \\
\hline & $\begin{array}{l}\text { Case } \\
3\end{array}$ & \#39 & 601.53 & 26.98 & 245.81 & 142.85 \\
\hline \multirow[t]{3}{*}{$\begin{array}{l}\text { Connecting } \\
\text { fenders }(\mathrm{kN})\end{array}$} & $\begin{array}{l}\text { Case } \\
1\end{array}$ & \#53 & 11513.4 & 25.71 & 1108.93 & 759.3 \\
\hline & $\begin{array}{l}\text { Case } \\
2\end{array}$ & $\# 53$ & 11526.72 & 30.1 & 1148.72 & 775.42 \\
\hline & $\begin{array}{l}\text { Case } \\
3\end{array}$ & \#53 & 11575.98 & 40.8 & 1231.01 & 800.51 \\
\hline
\end{tabular}

there is not much difference in the maximum forces on cable \#5 in the different pretension cases. However, the standard deviations of the cable \#5 forces increase as the pretension decrease, which is consistent with the trend of the relative motions as shown in Table 11. Similarly, the fender with the largest force in the mooring system is fender \#35 at the bow. There is not much difference in the maximum forces on fender \#35 when the pretension of the connecting cables get smaller, while the standard deviations decrease. This means that the decrease of the pretension reduces the probability of the collision events between FSRU and the wharf.

It can be observed from Table 12 that the most stressed cable in the connecting system changes in different pretension conditions. The maximum forces acting on the connecting cables has no specific change regulation. This is due to the complex hydrodynamic interaction between FSRU and LNGC under the action of wind, wave and current, which will also lead to complex relative motions. Moreover, ship type difference and asymmetric arrangement of connecting cables would change the whole force system of connecting cables. The maximum forces acting on the fender \#53 increase when the pretension decrease, so as the standard deviations. This indicates that the decrease of the pretension increases the maximum loads on the connecting fenders, as well as the probability of the collision events between FSRU and LNGC. In addition, it can be seen from Table 12 that the standard deviation of fender \#53 is much larger than that of fender \#46, which indicates that the collision between two ships is much more severe than that between FSRU and wharf. The severe collision between the two floating bodies in the multi-floating mooring system can be improved by increasing the pretension of the connecting cables.

\section{Conclusions}

In this paper, the damping lid method based on fairly perfect fluid hypothesis is used to simulate the hydrodynamic interaction between the two floating bodies. The time-domain coupled model of FSRU-LNGC side-by-side mooring system is established. The results between numerical results and model tests are compared to validate the correctness of the numerical calculation. The analysis of dynamic responses of the FSRU-LNGC side-by-side mooring system including the six degrees of freedom motion, relative motions, loads on cables and fenders is provided. The sensitivity study which is focused on the effects of the connecting cable's pretension is developed. A safe and reliable configuration of FSRU-LNGC multi-floating mooring system and the prediction of the dynamic responses of the system is obtained in this study. The design of side-by-side configuration and the numerical calculation method can provide reference for the dynamic response study of similar multi-floating mooring system.

Based on the dynamic responses analysis and sensitivity study results, as well as some guidelines proposed for further studies of mooring system design, we can further conclude:

(1) Under the given sea condition, the FSRU-LNGC side-by-side configuration designed in this paper meets the safety requirements.

(2) Compared with FSRU, LNGC has more severe motion responses. Overall, the forces acting on the cables and fenders of the connecting system are greater than that of the mooring system. In the connecting system, there are many collisions between the bows of the two ships, as well as between the sterns. The fenders at the bow experiences more collisions than the fender at the stern.

(3) The pretension of the connecting system can significantly affect the dynamic response of the FSRU-LNGC mooring system in sideby-side offloading operation. The severe roll motion of the two floating bodies and the severe relative roll motion between the two floating bodies in the multi-floating mooring system can be improved by increasing the pretension of the connecting cables.

(4) The effects of the pretension of the connecting system on the dynamic responses of the mooring system in side-by-side offloading operation are nonlinear. The severe collision between the two floating bodies in the multi-floating mooring system can be improved by increasing the pretension of the connecting cables.

(5) In this paper, the influence of irregular frequency on the calculation results is reduced by increasing the number of elements, but the irregular frequency is not completely removed. In the future research, corresponding methods will be considered to remove the irregular frequency in the calculation of multifloating body side-by-side mooring system.

\section{Declaration of competing interest}

The authors declare that they have no known competing financial interests or personal relationships that could have appeared to influence the work reported in this paper.

\section{Acknowledgments}

This work was financially supported by the National Natural Science Foundation of China (Project no. 51679177), the Key International (Regional) Cooperative Research Projects of the National Natural Science Foundation of China (Project no. 51720105011). These sources of support are gratefully acknowledged by the authors. 


\section{References}

Bai, K.J., 1972. A Variational Method in Potential Flows with a Free Surface. Ph.D. Dissertation, Department of Naval Architecture. University of California, Berkeley,

Buchner, Bas, Dijk, Van, Adri, Jaap De, Wilde, 2001. Numerical multiple-body simulations of side-by-side mooring to an FPSO. In: Proceedings of the Eleventh International Offshore and Polar Engineering Conference. International Society of Offshore and Polar Engineers.

Chakrabarti, S.K., 1978. Comments on second-order wave effects on large-diameter vertical cylinder. J. Ship Res. 22.

Chen, X.B., 2004. Hydrodynamics in Offshore and Naval Applications-Part I. Keynote Lecture in the 6th International Conference on HydroDynamics, Perth (Australia).

Chen, X.B., Malenica, S., 2005. Interaction hydrodynamique d'un ensemble de flotteurs sur la surface libre. In: 10emes Journees de l'Hydrodynamique, pp. 1-14 (Nantes, France).

Hong, S.Y., Kim, J.H., Cho, S.K., et al., 2005. Numerical and experimental study on hydrodynamic interaction of side-by-side moored multiple vessels. Ocean Eng. 32 (7), 783-801.

Hong, Yong-Pyo, Wada, Yojiro, Choi, Yong-Ho, et al., 2009. An experimental and numerical study on the motion characteristics of side-by-side moored LNG-FPSO and LNG carrier. In: Proceedings of the Ninth International Offshore and Polar Engineering Conference. International Society of Offshore and Polar Engineers.

Huang, W., Li, B., Chen, X., et al., 2018. Numerical and experimental studies on dynamic gangway response between monohull flotel and FPSO in non-parallel side-by-side configuration[J]. Ocean Eng. 149, 341-357.

Inoue, Yoshiyuki, Islam, M.R., 1999. Comparative study of numerical simulation and the experimental results for a parallely connected FPSO and LNG in waves. In: Proceedings of the Ninth International Offshore and Polar Engineering Conference. International Society of Offshore and Polar Engineers.

Journee, J.M.J., Massie, W.W., 2001. Offshore Hydromechanics, first ed. Delft University of Technology, p. 6.

Ministry of Communications of the People's Republic of China, 2009. Design Specification for LNG Terminal [S]. China Communications Press, Beijing.

Naciri, Mamoun, Waals, Olaf, de Wilde, Jaap, 2007. Time-domain simulations of side byside moored vessels: lessons learnt from a benchmark test. In: Proceedings of the
ASME 2007 26th International Conference on Offshore Mechanics and Arctic Engineering. American Society of Mechanical Engineers, pp. 801-811.

Newman, J.N., 2001. Wave effects on multiple bodies. Hydrodyn. Ship Ocean Eng. 3, $3-26$.

Newman, Nicholas, John, 1977. Marine Hydrodynamics. MIT press, Cambridge. OCIMF, 2008. Mooring Equipment Guidelines. Oil Companies International Marine Forum, London.

Pessoa, J., Fonseca, N., Soares, C.G., 2016. Side-by-side FLNG and shuttle tanker linear and second order low frequency wave induced dynamics. Ocean Eng. 111, 234-253.

Sun, L., Teng, B., Liu, C.F., 2008. Removing irregular frequencies by a partial discontinuous higher order boundary element method. Ocean Eng. 35, 920-930.

Sun, L., Taylor, P.H., Eatock Taylor, R., 2008. First and second order wave effects in narrow gaps between moored vessels. Marine operations specialty symposium, pp. 113-124.

Teng, B., Li, Y.C., 1996. A unique solvable higher order BEM for wave diffraction and radiation. China Ocean Eng. 10 (3), 333-342.

Vieira, D.P., Mello, P.C.D., Dotta, R., et al., 2018. Experimental investigation on the influence of the liquid inside the tanks in the wave behavior of FLNG vessels in sideby-side offloading operations. Appl. Ocean Res. 74, 28-39.

Xin, X., Yang, J.M., Xin, L., et al., 2014. Hydrodynamic performance study of two sideby-side barges. Ships Offshore Struct. 9 (5), 475-488.

Yangshan, Dai, Jinwei, Shen, Jingzheng, Song, 2007. Ship Wave Load [M]. National Defence Industry Press.

Yeung, R.W., 1975. A hybrid integral-equation method for the time-harmonic freesurface flows. In: Proceeding: First International Conference on Numerical Ship Hydrodynamics. Maryland, Gaithersburg, pp. 581-607.

Zhao, W.H., Yang, J.M., Hu, Z.Q., 2012. Hydrodynamic interaction between FLNG vessel and LNG carrier in side by side configuration. J. Hydrodyn. Ser. B 24 (5), 648-657.

Zhao, W., Yang, J., Hu, Z., et al., 2013. Hydrodynamics of an FLNG system in tandem offloading operation. Ocean Eng. 57 (Complete), 150-162.

Zhao, D., Hu, Z., Chen, G., 2017. Experimental investigation on dynamic responses of FLNG connection system during side-by-side offloading operation. Ocean Eng. 136, 283-293. 